\title{
NOTAS REFLEXIVAS SOBRE CONCEITOS QUE FUNDAMENTAM A UTOPIA COMO POSSIBILIDADE CONCRETA N'O PRINCÍPIO ESPERANÇA DE ERNST BLOCH
}

Rodrigo Sousa Fialho

Mestre em Filosofia pela Universidade Estadual do Ceará UECE. Professor EBTT do Instituto Federal do Maranhão IFMA. E-mail: rodrigo.fialho@ifma.edu.br.

Eduardo Jorge Oliveira Triandópolis

Doutor em Filosofia, Pós-doutor em Antropologia Histórica pela Universidade Livre de Berlim e Professor da Universidade Estadual do Ceará (UECE).E-mail: epolis@uol.com.br.

\section{RESUMO}

O presente artigo pretende alcançar a compreensão da seguinte questão: Como o filósofo alemão Ernst Bloch, à luz do marxianismo ${ }^{1}$, revisita e dá um novo significado ao problema da utopia, transportando o sentido desse termo que, originalmente, significa "não lugar" para topos (lugar) da práxis humana direcionada para frente, em outras palavras, direcionada para a sua concretização na história. Para tanto, abordar-se-á as concepções blochianas do onírico, contrapondo a noção de sonho diurno à de sonho noturno; da pulsão humana fundamental formulada a partir da crítica das teorias psicanalíticas de Freud, Adler e Jüng; do ainda não consciente, concebido com espaço privilegiado da utopia; e da função utópica, conceito intimamente associado à categoria possibilidade, apresentadas na principal obra do autor: O Princípio Esperança como fundamentos basilares do conceito de utopia concreta.

PALAVRAS-CHAVE: Pulsão. Sonho diurno. Ainda-não-consciente. Função utópica.

REFLECTIVE NOTES ON CONCEPTS WHICH FOUND UTOPIA AS A CONCERNED POSSIBILITY IN THE ERNST BLOCH HOPE PRINCIPLE 


\begin{abstract}
This article intends to reach an understanding of the following question: As the German philosopher Ernst Bloch, in the light of Marxianism, revisits and gives new meaning the problem of utopia, carrying the purport of that term which originally means "no place" for topos (place) of human praxis directed forward, in other words, directed for its concretization in history. To do so, we will approach the Blochian conceptions of the dream, contrasting the notion of daytime dream with that of night dream; of the fundamental human pulsion formulated from the critique of psychoanalytic theories of Freud, Adler and Jüng; of the still-not-conscious, conceived with privileged space of utopia; and the utopian function, a concept closely associated with the category of possibility, presented in the main book of the author: The Hope Principle as basic foundations of the concept of concrete utopia.
\end{abstract}

KEYWORDS: Pulsion. Daytime dream. Still-not-conscious. Utopian function.

\title{
1 INTRODUÇÃO
}

Embora etimologicamente o termo utopia possua um significado negativo, visto que designa "lugar que não existe", tal termo foi desenvolvido ao longo da história do pensamento e, paulatinamente, foi adquirindo novas conotações semânticas. O filósofo alemão Ernst Bloch retoma a discussão sobre a utopia acompanhando-a de uma fundamentação marxiana ${ }^{2}$ que, de fantasia ou impossibilidade, a eleva ao status de possibilidade objetiva real e concreta.

A concepção do mundo enquanto processo contínuo juntamente com a compreensão da necessidade de transformação do mundo confere à utopia o caráter de possível. Assim, na filosofia de Bloch, utopia adquire uma conotação positiva, pois passa a designar "lugar possível”. Esse lugar, porém, além de contar com a processualidade do mundo para tornar-se realidade material, necessita também da ação humana para ser edificado. Só a ação humana direcionada para frente é capaz de concretizar a utopia. A história é processual e como tal está permanentemente aberta à intervenção humana. As concepções blochianas de indivíduo enquanto sujeito agente na história e de mundo enquanto processo inacabado podem ser mais bem compreendidas se analisadas sob o prisma da décima primeira tese de Marx sobre Feuerbach: "Os filósofos têm apenas interpretado o mundo de maneiras diferentes; a questão, porém, é transformá-lo".

Por isso, o legítimo processo histórico tem como cerne o novo (novum), termo que indica a possibilidade concreta do ainda-não-consciente. Desse modo, clareia-se que, para que as ideias utópicas sejam concretizadas na história, faz-se necessário que os indivíduos que dispõem da consciência antecipadora não aceitem como natural as mazelas sociais, mas militem com o otimismo de quem sabe da possibilidade concreta da mudança por ter sua consciência 
desperta e o desejo ardente de ter uma vida melhor num mundo melhor para si e para os demais. Assim, a categoria blochiana de possibilidade permite aos indivíduos desejosos de viverem num mundo melhor entreverem as possibilidades de ação com vistas a transformá-lo.

Objetiva-se, com o presente artigo, conceder uma noção sobre como Ernst Bloch em $O$ Princípio Esperança fundamenta sua concepção de utopia concreta. Para tanto, discorrer-se-á sobre alguns dos conceitos presentes na mencionada obra que fundamentam a utopia como possibilidade concreta. Tais conceitos são pulsão, sonho diurno, ainda - não - consciente e função utópica.

\section{A PULSÃO HUMANA FUNDAMENTAL}

No ser humano um dos sinais da vida manifesta-se nos desejos, inquietudes e necessidades básicas urgentes. Além disso, o homem é um ser corpóreo, o que indica que possui uma estrutura fisiológica que depende de elementos externos para se manter. As inquietações naturais do homem o impulsionam a buscar a satisfação das carências que, quando não saciadas, põem abaixo o edifício corpóreo. Nenhuma pessoa está ou pode ficar livre dessas inquietações. Essa intranquilidade com a qual o ser humano busca o indispensável é chamado de instinto de sobrevivência ou autopreservação e é sintomática, pois significa que algo lhe falta.

Dessa forma, o ansiar, no sentido de desejar insistentemente, é a única condição sincera de todos os seres humanos. Esse ansiar consiste no almejar sentido que se direciona para fora de si, realiza um movimento de dentro para fora à procura de algo que lhe dê saciedade, não se dá somente uma única vez e deve ser saciado sempre que necessário. Assim, o ansiar torna-se uma busca que se caracteriza por orientar-se em direção a um alvo. O rumar-para do buscar divide-se desde sempre nesta ou naquela pulsão de acordo com aquilo para o que está direcionado. Bloch explica que, no ser humano, cada pulsão é individualmente direcionada:

[...] Ele sempre busca preencher, mediante algo exterior, um vazio, algo de que carece o almejar e ansiar, algo que falta. Esse algo diferenciado, compreendido como o pão ou a mulher ou o poder e assim por diante, é o que subdivide o movimento direcionado para um alvo nas duas diferentes pulsões [...] (BLOCH, 2005, p. 50).

Pulsão é, conforme o trecho supracitado, uma necessidade orientada para um alvo, isto é, uma força que sai à procura daquilo que satisfaz uma necessidade. Dessa forma, a pulsão sentida é o específico de cada uma das paixões, ou seja, existe a pulsão da fome, do sexo, do poder etc., o que leva a pensar que o corpo é, em certa medida, determinado pelas pulsões. 
Porém, por mais que aparentemente sejam as pulsões que, de algum modo, determinem as ações e reações do corpo, ou ao menos parte delas, Bloch explica que: "Apesar dessa aparência porventura destituída de sujeito, nada no corpo permite fazer das pulsões portadoras de si mesmas" (BLOCH, 2005, p. 52).

Bloch explica que este conceito possui o mesmo significado de necessidade. Porém como essa palavra não designa movimento em direção a um alvo, ele prefere manter sempre o uso do termo pulsão. A pulsão não pode existir fora do corpo, ao contrário, só nele existe e atua. Bloch salienta ainda que é no instinto que a pulsão manifesta essa aparência de aspecto destituído de sujeito. Todavia, também o instinto participa da preservação do corpo e é utilizado de acordo com a medida de tal participação no momento em que o corpo age em vista do seu benefício. Por conseguinte, é sempre o corpo que age nas pulsões e não o contrário. Bloch salienta a dificuldade humana para saciar os desejos, quanto mais os desejos são satisfeitos mais novos desejos aparecem:

[...] O ser humano é o animal mais difícil de saciar: é ele o animal que, para a satisfação de seus desejos, não vai direto ao ponto. Se lhe falta o necessário à vida, ele sente essa carência como nenhum outro ser: visões da fome emergem. Se ele tem o necessário, com o desfrute emergem novos apetites, que molestam de outra maneira e não menos de que antes o fazia a pura carência [...]. Em suma, está ficando claro que o ser humano é um ser de pulsões tão cambiantes quanto amplo, um amontoado de desejos cambiantes e geralmente mal ordenados [...] (BLOCH, 2005, pp. 53-54).

A partir do trecho supracitado pode-se indagar: se são diversas as pulsões, qual ou quais delas são as mais importantes para a vida humana? A esta indagação, Bloch responde afirmando que há várias pulsões fundamentais, em certos momentos uma age com mais força, em outros momentos outra e há ainda momentos que algumas pulsões agem ao mesmo tempo. Cabe a cada indivíduo buscar a saciedade dos seus desejos e vontades. Há, todavia, algo do qual o corpo possui maior necessidade e que, devido a isso, precisa ser buscado antes das demais, ou seja, requer prioridade. Por apresentar-se como fundamental para existência de todo indivíduo esse algo precisa ser almejado mais do que outras coisas e de maneira singular. Em vista disso tornamos à questão: qual é a pulsão fundamental do ser humano? Antes de dar resposta a tal questão, Bloch efetua uma análise crítica da teoria de três teóricos da psicanálise que desenvolveram suas próprias concepções de pulsão fundamental: Freud, Adler e Jüng. Para o primeiro, o instinto sexual é o mais latente de todos. O segundo atesta que a vontade de 
potência é o principal e o terceiro apela para um exacerbado anarquismo, ao defender a dionisíaca aversão à razão como o instinto humano fundamental.

As respostas sugeridas pelos mencionados psicanalistas requerem maior atenção. $\mathrm{Na}$ concepção de Freud o ser humano é movido a sexo. Esse é o combustível que coloca esse ser em movimento. Ou seja, para ele, a libido rege a vida. Para Adler, o indivíduo humano deseja, antes de qualquer outra coisa, dominar, sair de baixo para o topo e aí permanecer. "Vaidade, ambição e 'protesto masculino' são os afetos nos quais essa pulsão fundamental se manifesta de forma mais visível" (BLOCH, 2005, p. 60).

E se em Freud, o inconsciente é o porão da consciência e o que está escondido nele deve emergir na luz da consciência, em contrapartida, para Jung, o inconsciente é valorizado e considerado a moradia dos arquétipos. Se de certa maneira, o inconsciente, na concepção de Freud, atrapalha o ser humano, para Jüng, ele é a "salvação" deste mesmo ser. Enquanto para Freud, o doente é induzido a recordar do inconsciente só para dele se libertar, para Jüng, o doente é recordado do inconsciente para que mergulhe até as suas profundezas.

Bloch faz duras críticas ao passadismo presente nas teorias de Freud, Adler e Jüng. Para ele, as pulsões apresentadas pelos três psicanalistas como fundamentais estão, de certa forma, distantes do corpo humano, que em primeiro lugar, deseja conservar-se. Além disso, Os três concebem o inconsciente como algo situado no passado da evolução histórica, como um objeto velho guardado no porão. Por isso, o filósofo alemão considera que nenhum deles possui uma pré-consciência do novo.

As pulsões humanas fundamentais, segundo Bloch, não são estabelecidas e determinadas de uma vez para sempre. Essas variam de acordo com condições materiais, tais como época e classe social. Portanto, a pulsão é um produto histórico-social. Mas nem a libido, nem a vontade de potência e nem o proto-Dionísio podem ser consideradas fundamentais, pois nenhuma delas é tão essencial quanto a pulsão da autoconservação. A partir dessa análise crítica, Bloch esclarece que, entre as pulsões, há uma que é indispensável para a sobrevivência humana: a fome.

A fome é a pulsão que leva a pessoa faminta a bater nas portas das casas dos mais abastados em busca do que pode satisfazer a sua carência. O faminto sofre com a privação daquilo que é indispensável a todos os seres humanos e o mesmo sofrimento que o dilacera também o move a, muitas vezes sem forças, sair em busca do alimento para manter-se vivo. É por isso que o instinto de sobrevivência é a pulsão mais importante para todos os seres humanos. Uma pessoa 
é capaz de viver sem amor, sem poder, sem regressão ao inconsciente de ancestrais longínquos, mas não sem o alimento que sacia a fome.

Apenas a fome possui um caráter de urgência. E uma vez saciada, esta não desaparece de uma vez por todas, ela torna e novamente precisa ser saciada. Esse é um processo constante em todos os seres humanos. E quando essa exigência de saciedade não é atendida, a fome, o sofrimento causado pela privação do alimento, pode, segundo Bloch, converter-se numa alavanca para o desencadeamento de uma revolução. Urge no sujeito faminto a rebeldia, a indignação que o provoca a querer mudar a situação de privação na qual se encontra. Conforme Bloch, "o não ao ruim existente e o sim ao melhor em suspensão são acolhidos pelos carentes no interesse revolucionário" (BLOCH, 2005, p. 78). Dessa forma, além da autopreservação, o si-mesmo também expande, revoluciona.

[...] da fome esclarecida economicamente procede a resolução pela suspensão de todas as relações em que o ser humano é um ser oprimido e perdido. Muito antes dessa resolução e por muito tempo dentro dela, o impulso rumo a satisfação será um impulso que sobrevive imaginativamente ao que está ao alcance da mão [...] (BLOCH, 2005, p. 78).

Em seguida, Bloch prossegue dizendo:

Por isso é conseqüente que, antes de um arquiteto [...] conhecer o seu plano, ele tenha elaborado esse plano, que ele tenha percebido a realização desse plano como um sonho brilhante, que o impulsiona decisivamente para a frente [...] (BLOCH, 2005, p. 78).

Com base no trecho acima, pode-se inferir que, para Bloch, uma das características do ser humano é sua capacidade de projetar imaginativamente a imagem do objeto desejado. Essa imagem é capaz de restaurar as forças do indivíduo e o motivar a buscar com toda disposição e prontidão aquilo que ele deseja. Assim, a fome funciona como uma injeção de ânimo que, se por um lado, pode arrefecer os ânimos, por outro, pode reavivar os ânimos de uma pessoa e estender-se até a conquista da almejada vida melhor. Desse modo, plasmam-se sonhos diurnos, cuja origem e procedência são sempre uma provação da qual o indivíduo quer se libertar. Portanto, para Bloch, a fome é uma espécie de fonte de onde jorram sonhos diurnos.

\section{O SONHO DIURNO EM CONTRAPOSIÇÃO AO SONHO NOTURNO}

Em geral, a palavra sonho remete a alguém que está em pleno sono, nas profundezas do 
repouso, mas os sonhos não se manifestam apenas no indivíduo adormecido, é possível sonhar também quando acordado. A fundamentação da utopia concreta passa pela carga semântica que Bloch confere ao sonho diurno. Essa significação blochiana é engendrada com base na crítica mordaz à concepção freudiana que reduz o sonho desperto ao sonho noturno. Segundo Freud, os sonhos diurnos não passam de um prelúdio dos sonhos noturnos que necessitam de interpretação para que se descubra a causa do recalque do paciente, ou seja, o sonho é reduzido a uma mera via para a descoberta do que foi reprimido.

Desse modo, na teoria freudiana, mesmo uma adequada interpretação dos sonhos noturnos não implica em algo novo na vida de um indivíduo, ao invés disso, servirá somente para identificar a origem do problema psicológico que finca suas raízes no passado. $\mathrm{Na}$ concepção de Bloch, a freudiana redução do sonho diurno ao sonho noturno é absurda, pois, para ele, os sonhos despertos antecipam uma realidade que está a caminho, orienta o ser humano para o futuro, enquanto os sonhos noturnos remetem sempre ao que passou. Assim, os sonhos diurnos, que possuem um caráter universal - "A vida de todos os seres humanos", escreve Bloch, "é perpassada por sonhos diurnos [...]" (BLOCH, 2005, p. 14) - são como uma mola propulsora que não permite ao ser humano cair no conformismo, no marasmo e não deixa que a situação adversa seja aceita como natural.

A função dos sonhos diurnos é ajudar os indivíduos a enxergar a possibilidade de concretização das ideias utópicas no mundo. Eles têm a capacidade de ampliar a visão humana a ponto de fazê-la antever no presente um futuro melhor: "Enquanto o ser humano se encontrar em maus lençóis, a sua existência tanto privada quanto pública será perpassada por sonhos diurnos, por sonhos de uma vida melhor que a que lhe coube até aquele momento [...]" (BLOCH, 2005, p. 15). Nesse sentido, o ser humano é naturalmente impelido para uma vida melhor, e não para um estado de mazela, de carência perpétua.

Dito de outra forma, a função do sonho diurno é manter acesa a chama da esperança, termo ao qual Bloch confere significado laicista, diferente do significado judaico-cristão (não há aqui a expectativa da vinda do messias salvador e instaurador de uma ordem justa). O sonhar acordado é um sonhar direcionado para a frente, que antecipa a utopia de forma imagética, e isso é que impulsiona o ser humano a prosseguir, ainda com mais força, em busca da realização desse sonho por uma vida melhor. Além disso, os sonhos diurnos antecipam o mundo em que os seres humanos desejam viver e o mundo almejado é aquele que proporciona uma vida livre da miséria material. O próprio Bloch define o sonho diurno como uma possibilidade concreta: 
Com efeito, os seres humanos de forma alguma sonham apenas à noite. Também o dia possui bordas crepusculares, também ali os desejos se saciam. Diferentemente do sonho noturno, o sonho diurno desenha no ar repetíveis vultos de livre escolha, e pode se entusiasmar e delirar, mas também ponderar e planejar. De maneira ociosa (que, contudo, pode ser muito semelhante à da musa de minerva), ele persegue ideias políticas, artísticas, científicas. O sonho diurno pode proporcionar ideias que não pedem interpretação, e sim elaboração - ele constrói castelos de vento com plantas já desenhadas nem sempre meramente fictícias [...] (BLOCH, 2005, p. 88).

Enquanto os sonhos noturnos são manifestações fabulosas do conteúdo do inconsciente ${ }^{3}$, e que precisam ser interpretados, os sonhos diurnos não precisam de interpretação, mas de esquematização, elaboração de uma estratégia de ação que visa a realização desses sonhos na história. No sonho diurno a imagem de um mundo melhor possível é antecipada e o sujeito passa a ter a consciência dessa possibilidade e do caminho para torná-la realidade tangível. Por conseguinte, o que outrora parecia impossível, isto é, fora do alcance humano, descortina-se como possibilidade concreta diante daquele que sonha de olhos abertos.

O sonho diurno possui quatro características específicas que o distingue do sonho noturno. A primeira característica do sonho acordado é o domínio do sujeito consciente sobre o sonho. O sujeito que sonha noturnamente não escolhe com que ou com quem sonhar, não escolhe o momento do início nem do fim do sonho, não escolhe se o sonho será colorido ou em preto e branco, não escolhe nem mesmo se ao acordar lembrará ou não do que sonhou. O sonho noturno é absoluto e imperioso.

Em contrapartida, no caso do sonho diurno é o sonhador que domina o sonho e não o sonho que domina o sonhador. Mesmo que no sonho diurno, assim como no noturno, a pessoa que sonha se encontre em estado de relaxamento, a viagem imaginativa não comanda de forma arbitrária aquele que sonha, ao contrário, este é que tem total poder de decisão sobre o conteúdo do sonho. Portanto, a primeira característica do sonho diurno é a liberdade que o sujeito tem de conduzir o próprio sonho.

A segunda característica do sonho desperto é o ego inalterado ou preservado. Aquele que sonha acordado tem plena consciência da vontade, que se mantém consciente na direção de uma vida melhor. O protagonista do sonho desperto é, em todos os casos, o indivíduo adulto, pois ele tem plena consciência de si. Para Bloch, "o ego está preservado sempre na força adulta, como experiência adulta de unidade de processos psíquicos conscientes” (BLOCH, 2005, p. 92). 
No sonho acordado o eu faz-se integralmente presente, já no sonho noturno - ao menos na concepção de Freud - o eu se faz presente enquanto instância censuradora, na medida em que força as alucinadas realizações do desejo a se camuflarem diante de seu olhar observador e corretivo. Portanto, no sonho noturno, o ego exerce uma função de censura moral. Em contrapartida, no sonho diurno o eu não exerce nenhuma censura sobre os conteúdos não convencionais do seu desejo. Isso porque é próprio do eu do sonho desperto aderir ao ideal desejado. O sonho diurno não poderia exercer censura moral, mesmo porque o seu ego constrói a si mesmo e as imagens utópicas que impulsionarão o sujeito que sonha a procurar efetivar o conteúdo do seu sonho.

A terceira característica é a de transformar o mundo. A pessoa que dorme se encontra em pleno repouso, "desligada" do mundo, nada tem que fazer pelos outros, já o ego de quem está desperto tende a se expandir na direção dos outros e objetiva transformar a vida de todos. O sonho diurno tem a possibilidade de ser concretizado, pode tornar-se a nova habitação que a humanidade tanto almeja. Essa é a dimensão utópica do sonho acordado, que projeta o mundo melhor como o mais belo mundo em imagens completas, mas que ainda está em gestação. Segundo Bloch, os sonhos diurnos são traduzidos por meio da arte.

Devido a isso, o interlocutor do indivíduo que sonha acordado tem facilidade para compreender a mensagem que lhe é transmitida e essa mensagem pode ser irradiada via poesia, romance, teatro, pintura etc. Consequentemente, outro fator que diferencia o sonho diurno do noturno é a fácil comunicabilidade do sonho acordado, ao passo que o sonho noturno não pode ser disseminado com a mesma facilidade devido ao fato das imagens desse tipo de sonho nem sempre condizerem com a realidade e, por isso, para que sua comunicabilidade faça sentido depende de interpretação. O sonho desperto é, portanto, caracterizado por orientar o ser humano a mudar o mundo.

A quarta e última característica do sonhar acordado é ir até o fim. O sonho diurno não se conforma apenas com a realização fictícia, poética ou imagética do seu desejo. Ele quer mais, quer ver o desejo tornar-se realidade. Ao contrário do sonho noturno, que termina com o despertar do sonhador, o sonho diurno vai com o seu desejo até o fim. O ponto de partida da fantasia desperta bem como da fantasia noturna são os desejos. Porém, ao inverso do sonho noturno, o sonho diurno quer concretizar-se, isto é, quer ser realizado e, conforme Bloch, o mundo é um espaço aberto à sua realização.

Por esta razão, enquanto o sonho noturno tem necessidade de ser interpretado, o sonho 
acordado necessita de efetivação. Enquanto o sonho noturno, em geral, não passa de mera erupção de imagens desordenadas que podem não ter significado algum, o sonho diurno é uma possibilidade real, objetiva, porquanto, o próprio mundo concebido como um processo inacabado como que convida o sonho desperto a ser concretizado. Dessa forma, o sonho diurno é algo para ser planejado no presente e executado no futuro.

\section{O AINDA NÃO-CONSCIENTE}

Em geral, o termo consciência reporta-se a aquilo de que se tem clareza, a algo que se enxerga e compreende com facilidade. Em contrapartida, o termo inconsciente aludi a algo "misterioso", termo que remete ao que é obscuro.

A concepção passadista que a psicanálise produz do inconsciente é alvo de severas críticas de Bloch. Essa crítica se dá precisamente devido ao fato do inconsciente ter sido reduzido a algo do qual não se tem lembrança. E quando esse algo, alojado no inconsciente torna-se consciente, tal fato não passa de uma recordação, de uma rememoração de algo que jazia esquecido no porão da consciência e que, possivelmente, ocorreu num passado longínquo.

Na psicanálise a função do inconsciente é auxiliar o paciente a, por meio da regressão palavra que remonta ao passado - encontrar a raiz do seu problema psíquico, seja esse uma neurose ou psicose ou outro problema psíquico qualquer. "Desta forma, contudo, mesmo o psiquicamente inconsciente", diz Bloch, "foi pensado até hoje meramente como algo que se situa abaixo da consciência e submergiu diante dela” (BLOCH, 2005, p. 116).

Nada há de novo, trata-se apenas da emersão de algo que outrora havia submergido. A isso que Bloch designa como mero não-mais-consciente, por se tratar de algo que foi esquecido, que fugiu da lembrança, mas que não contém nada de novo, diferentemente do ainda-nãoconsciente, termo que carrega em si o novo, no sentido de algo inédito. Com base nisso, Bloch define o lugar do não-mais-consciente e do ainda-não consciente. O âmbito do primeiro é o sonho noturno, o do segundo é o sonho diurno. É desse modo que, segundo ele, surge a última certificação psicológica do sonho acordado: "Ainda não existe uma psicologia do inconsciente do outro lado, do alvorecer para frente. Esse inconsciente passou despercebido, embora represente o espaço propriamente dito da disposição para o novo" (BLOCH, 2005, p. 117).

Para esclarecer as diferenças entre o não-mais-consciente e o ainda-não-consciente, em primeiro lugar, é preciso saber que, para E. Bloch, o ainda-não-consciente não está subordinado à consciência presente e sim a uma consciência futura. $\mathrm{O}$ ainda-não-consciente é o lugar 
psíquico do surgimento do novo, nele encontra-se o conteúdo da consciência que ainda não se manifestou de forma explícita, que brota a partir do futuro.

Este é o espírito do sonhar para frente, isto é, o espírito imbuído de algo que ainda-não veio, mas está a caminho. E o que é a esperança senão o anelo por bens que estão a caminho. A esperança blochiana consiste precisamente na expectativa dos bens ou mesmo de um mundo melhor que a humanidade tornará realidade.

Conforme Bloch, o ainda-não-consciente possui lugares privilegiados. O primeiro deles é a juventude. A juventude é um tempo de entusiasmo e de ousadia. Nessa fase da vida, a pessoa é capaz de arriscar, de se aventurar e de ter fé no que, para muitos, é considerado impossível. O jovem é aquele que se deixa impulsionar pela agitação que estremece seu interior. "Os anos verdes", afirma Bloch, "estão repletos de alvoreceres para a frente. Mais da metade deles consiste de estados ainda-não-conscientes" (BLOCH, 2005, p. 118). De fato, Bloch não poderia deixar de ver na juventude um lugar privilegiado do ainda-não-consciente, visto que à juventude pertence o futuro.

O segundo lugar privilegiado do ainda-não-consciente é o momento de mudança de época. É nesse período que a juventude tem a possibilidade de adquirir maior clareza sobre o sonhar para a frente. Esse é o momento em que a juventude pode ampliar sua visão de mundo e assumir a responsabilidade da mudança. Exemplo disso foram os protestos liderados por estudantes franceses que agitaram o Mundo, mas, sobretudo a Europa no ano de 1968.

Nessa época, a juventude reivindicava liberdade rejeitando a ordem estabelecida e a sociedade capitalista que prioriza o consumo em detrimento das relações humanas. Eles desejavam mudar os valores morais vigentes por valores mais abertos, mais adequados aos tempos modernos e, para isso, foram protagonistas de um acontecimento histórico que ficou mundialmente conhecido como o maio de $68^{4}$. Os eventos ocorridos em 1968 são um exemplo claro de jovens engajados na mudança de uma época. Épocas de mudanças são épocas de gestação de uma nova sociedade, portanto, épocas repletas do ainda-não-consciente.O terceiro lugar privilegiado do ainda-não-consciente é a produtividade intelectual. E se a juventude tem ainda maior possibilidade de ser protagonista das mudanças nos tempos de revolução, também na criação intelectual ela possui papel de destaque. Um pequeno trecho do poema $O$ Torrão $e o$ Seixo de Willian Blake, expressa bem essa energia e protagonismo da juventude: 
Sacrifica por outro o bem-estar, $\mathrm{E}$, a despeito do inferno,

(BLAKE, 2010, p. 3-4).

Por conseguinte, a razão de ser da produtividade é trazer à luz a feição do conteúdo ambicionado, é nada mais nada menos, a função de antecipar imageticamente o tão almejado ainda-não. Após explicitar as fronteiras e os lugares privilegiados do ainda-não-consciente, Bloch expõe também a barreira que, por bastante tempo, obstruiu o conceito do ainda-nãoconsciente. Na verdade, tal exposição consiste na resposta à questão sobre o porquê em seguida a descoberta do consciente e do subconsciente, o ainda-não-consciente sequer foi notado.

Para responder essa questão, o filósofo alemão faz uma análise crítica da evolução histórica da psicanálise. Segundo Bloch, Leibniz é o primeiro a caracterizar psicologicamente fenômenos inconscientes. Ele chama atenção para a teoria de Leibniz que defende o princípio da continuidade universal isenta de lacunas. Essa lei do contínuo não deixa margem para espaço vazio em parte alguma. Mesmo que a impressão de que haja espaço vazio seja possível, não passa de falsa impressão, pois todo espaço é preenchido por algo tão pequeno que chega a ser imperceptível.

Mas da mesma forma que "existem minúsculos impulsos que determinam o movimento também existem os que determinam a intensidade representativa da consciência, em diferentes graus deacordo com a clareza e a inteligibilidade: petites perceptions insensibles "pequenas percepções insensíveis” (BLOCH, 2005, p. 132). Então, para ilustrar sua teoria, Leibniz dá exemplos de percepções minúsculas e imperceptíveis, mas que com um certo nível de acúmulo, tornam-se conscientes, "como no caso do barulho das ondas" (BLOCH, 2005, p. 132).

Com isso, o conceito do inconsciente é resultado da lei do contínuo. Aqui Bloch reforça sua crítica à submissão do conceito de inconsciente ao de consciente. $\mathrm{O}$ inconsciente sempre foi conhecido como subconsciente, isto é, sempre esteve abaixo do consciente. As pequenas percepções insensíveis, por exemplo, não podem ser percebidas devido a força da consciência. A crítica de Bloch é que, compreendidas assim, elas não são elementos capazes de gerar algo novo. Ocorre que o próprio Leibniz sinaliza na direção de uma consciência distinta da que existe na alma.

Dessa forma, a consciência por si mesma já não é mais a principal característica do espírito. Desenvolve-se assim o conceito de inconsciente, mas também adquire forma o espaço onde o ainda-não-consciente encontrava-se incubado. É que esse disfarce do "ainda-não- 
consciente entrou em cena", de acordo com Bloch, "com pseudomorfismos singulares" (BLOCH, 2005, p. 133), um deles é o Romantismo, alvo de duras críticas do filósofo alemão.

A tônica da crítica blochiana ao Romantismo é a mesma aplicada na crítica à tradição filosófica e à psicanálise. O Romantismo é de certa forma, um olhar saudosista para as coisas consideradas positivas do passado, inclusive e principalmente do modo de vida medieval:

[...] De modo praticamente impossível de reconstruir, os românticos ficaram à mercê do passado, numa lex continui que - fiel ao movimento reacionário - erguia apenas castelos feudais na noite mágica banhada em luar. O histórico se associou ainda mais com o arcaico e este com o telúrico, de tal forma que o interior da história logo assumiu a aparência do interior da Terra [...]. Toda produtividade, e justamente o caráter expectante em que o Romantismo paradoxalmente é tão rico, mergulhou em reflexões sobre imagens antigas, o passado, o imemorial, o mito, erguendo assim uma barreira contra o futuro, visto cada vez mais como poeira, vazio, vento [...] (BLOCH, 2005, pp. 134-135).

Observa-se, na passagem acima, que a grande reclamação de Bloch contra o Romantismo é, fundamentalmente, ao saudosismo e ao anacronismo que boicotam o futuro, desviando-se radicalmente do ainda-não-consciente. No Romantismo tanto a produtividade quanto a mudança de época são renegados, o que indica que a juventude é orientada para trás, na contramão dos próprios anseios, por isso, não há espaço para o novo. Ou seja, o Romantismo fez a opção pelo arcaico em detrimento do novo. Essa opção é muito bem ilustrada no quadro A Peregrinação a Ilha de Citera $^{5}$ de Antoine Wateau, uma representação pictórica de uma utopia.

No caso da moderna utopia da peregrinação à ilha do amor, a imagem de uma sociedade ideal como Citera, uma ilha onde reinam o amor e a harmonia entre os indivíduos e onde a natureza exuberante e bela é o espaço dessa vida de amor. "Também o fundamento realmente arcaico da memória, ao qual remontam tantas imagens da esperança - a saber: os arquétipos idade de ouro e paraíso, - situa-se como algo aguardado no outrora do tempo" (BLOCH, 2005, p. 99). Bloch considera a obra de arte de Wateau uma utopia inautêntica devido ao fato de não expressar de um mundo melhor possível para todos, mas de um mundo completamente fictício, sem possibilidade de concretização na realidade.

\section{A FUNÇÃO UTÓPICA}

O olhar para a frente torna-se refinado na medida em que se torna consciente. Assim, o sonho tende a ser nítido, a intuição certeira. Para o surgimento da função utópica, faz-se 
necessário que o ainda-não-consciente se torne consciente de si enquanto algo que está para vir, que é uma emergência ciente do fato de que está emergindo. É nesse momento que a esperança, não enquanto mero sentimento ou emoção, mas enquanto afeto expectante desabrocha de maneira "consciente-ciente como função utópica" (BLOCH, 2005, p. 144).

"Na formulação abstrata das utopias a função utópica ainda carece de maturidade", diz Bloch, “[...] ou seja, ainda não há um sujeito sólido que o respalde e ela não tem um possível real como referência" (BLOCH, 2005, p. 114). Dito de outra maneira, na formulação abstrata das utopias, não se encontra a categoria possibilidade, as utopias abstratas não são caracterizadas pelo ainda-não, ao invés, à semelhança das fantasias quiméricas, reduzem-se a algo impossível. O próprio Bloch explica a razão pela qual, diferentemente das utopias abstratas, sua proposta de utopia é, na realidade, uma utopia concreta:

[...] O ponto de contato entre sonho e vida, sem o qual o sonho produz apenas utopia abstrata e a vida, por seu turno, apenas trivialidade, apresenta-se na capacidade utópica colocada entre os próprios pés, a qual está associada ao possível-real. Uma capacidade que, guarda pela tendência, supera e já existente não só na nossa natureza mas também no mundo exterior em processo como um todo. Com isso, aqui teria lugar o conceito de utópico-concreto, apenas aparentemente paradoxal, ou seja um antecipatório que não se confunde pela imaturidade de um socialismo meramente histórico-abstrato (BLOCH, 2005, p. 145).

No trecho acima, Bloch indica que sua compreensão de possibilidade de realização das ideias utópicas na história se dá pela tendência de mudança implícita tanto na própria natureza humana, quanto na totalidade do mundo, que é por ele concebido enquanto processo inacabado. Por conseguinte, é o próprio mundo que fornece aos indivíduos a condição para transformá-lo, isto é, para atuar sobre ele de modo a realizar as ideias utópicas.

Com base no que foi dito, é a partir da compreensão marxiana de mundo, de história e de homem que Bloch confere à sua utopia o adjetivo concreta. As utopias renascentistas, por exemplo, eram apenas representações de uma vida melhor projetada no futuro, mas impossíveis de serem concretizadas na realidade. Tais utopias significavam não apenas o que etimologicamente significa o termo utopia, a saber, "lugar nenhum", o que as torna, não um ainda-não, mas algo que jamais será. Correlativo a função utópica é o processo que ainda-não se realizou, mas está em vias de se realizar. Por conseguinte, a função utópica alinha-se a tudo o que é nascente no mundo. 


\section{CONSIDERAÇÕES FINAIS}

No magistral $O$ Princípio Esperança, Bloch aborda criticamente a questão da utopia enquanto fantasia literária, transpondo, após a elaboração dos conceitos sobre os quais se refletiu, a utopia para um outro patamar. Ao reelaborar as noções de pulsão, sonho diurno, e elaborar as noções de ainda-não-consciente e função utópica, ressignifica a utopia, termo que outrora fora subsumido a mera expressão literária dos mais profundos anseios humanos. Os Conceitos explorados ao longo do artigo desvelam um mundo inconcluso, aberto à transformação que pode ser operada pelo ser humano, cujos desejos impelem a orientar-se para o futuro:

Redobrando-se a coragem e o saber, o futuro não virá como fatalidade sobre o ser humano, mas o ser humano virá sobre o futuro e ingressará como o que é seu. Aqui, o saber, que necessita da coragem e sobretudo da decisão, não pode assumir a forma mais comum do saber habitual, a forma contemplativa, pois o saber meramente contemplativo se refere forçosamente ao que já está concluído e já passou, não tem meios diante de coisas presentes e é cego para o futuro (BLOCH, 2005, p. 196).

A partir do exposto acima se vê que em oposição ao saber inclinado para o passado, ao já concluído, o saber necessário para a decisão não é o mero saber contemplativo, "ao contrário", diz Suzana Albornoz, "prende-se ao processo do mundo e toma o partido ativo do bem, que aí encontra progressivamente passagem, do que é digno do homem no processo" (ALBORNOZ, 1985, p. 63). Bloch, portanto, fundamenta sua noção de utopia concreta a partir dos conceitos elaborados e reelaborados n' O Princípio Esperança, com os quais lança as bases de uma filosofia do futuro.

\section{NOTAS}

${ }^{1}$ É o indivíduo ou proposição que se remete ao pensamento de Marx sem pertencer interpretação ortodoxa do marxismo.

${ }^{2}$ N'O Princípio Esperança, Bloch observa que a teoria psicanalítica de Freud concebe os sonhos noturno como manifestações fantásticas do inconsciente que precisam de intepretação para fazerem sentido.

${ }^{3} \mathrm{O}$ evento conhecido como o Maio de 68 simbolizou um momento de grandes transformações políticas, culturais e comportamentais que marcaram a segunda metade do século vinte no ocidente. Foi essencialmente protagonizado por jovens estudantes europeus. Mas, o movimento eclodiu quando o líder radical Rudi Dutschke sofreu um atentado, em 11 de abril de 1968. Influenciados pelas teorias revolucionárias da chamada Escola de Frankfurt, os estudantes alemães receberam o apoio de intelectuais progressistas, como os escritores Heinrich Böll e Günter Grass, e de grandes jornais como o "Der Spiegel" e o "Die Zeit". Movimentos sociais como o pacifismo, o ecologismo e o feminismo surgiram inspirados nas mudanças estabelecidas no Maio de 1968.

${ }^{4}$ Um dos quadros mais conhecidos de Antoine Wateau. Trata-se uma pictórica utopia, no caso, do mito moderno do embarque à ilha do amor. Ao contrário da maioria das utopias, nada tem a ver com uma utopia das classes trabalhadoras que imaginam para si uma sociedade melhor no futuro, mas de uma utopia ao gosto de um público predominantemente aristocrático que, na medida do possível, não precisava de trabalho profissional para viver. Por isso dispunham de mais tempo para necessidades humanas como o amor. 


\section{REFERÊNCIAS BIBLIOGRÁFICAS}

ALBORNOZ, Suzana. Ética e Utopia: Ensaio sobre Ernst Bloch. Porto Alegre: Ed. Movimento, 1985.

BLAKE, Willian. O Torrão e a Rocha. Revista Yawp. vol. 5, 2010. Disponível em: $<$ http://dlm.fflch.usp.br/sites/dlm.fflch.usp. br/files/texto1_0.pdf > . Acesso em 26 ago. 2017.

BLOCH, Ernst. O Princípio Esperança. vol. I. Tradução: Nélio Schneider. Rio de Janeiro: Ed. EdUERJ: Contraponto, 2005.

$$
\text { . O Princípio Esperança. vol. II. }
$$

Tradução: Werner Fuchs. Rio de Janeiro: Ed. EdUERJ: Contraponto, 2006.

. O Princípio Esperança. vol. III. Tradução: Nélio Schneider. Rio de Janeiro: Ed. EdUERJ: Contraponto, 2006.

DE SÁ, A.F. Haverá ainda lugar para a Utopia Política? In LusoSofia. Covilhã, 2009. Disponível em: < http://www.lusosofia.net/textos/sa_alexand re_franco_de_havera_ainda_lugar_ para_a_utopia_politica.pdf>. Acesso em 25 ago. 2017.

FURTER, Pierre. Dialética da esperança. Rio de Janeiro: Paz e Terra, 1974.

GIMBERNAT, J.A. La Conciencia de La Liberdad: La filosofia como filosofia de La historia em Ernst Bloch. ISEGORIA, Espanha, vol. 4, 1991. Disponível em: $<$ http://isegoria.revistas.csic.es/index.php/i segoria/article/view/352/353>. Acesso em 25 ago. 2017.

MÜNSTER, Arno. Ernst Bloch: filosofia da práxis e utopia concreta. São Paulo: Ed. UNESP, 1993.

.Utopia, Messianismo e Apocalipse Nas Primeiras Obras de Ernst Bloch. São Paulo: Ed. UNESP, 1997.

FIALHO, R. S.; TRIANDÓPOLIS, E. J. O. Notas Reflexivas Sobre Conceitos que Fundamentam a Utopia Como N'o Princípio Esperança de Ernst Bloch. Complexitas - Rev. Fil. Tem. Belém, v. 2, n. 2, p. 58-73, jul./dec. 2017. Disponível em:< http://www.periodicos.ufpa.br/index.php/complexitas/article/view/5419>. Acesso em: 07 de janeiro de 2019. 